\title{
Potentiometric and NMR spectroscopic study of protonations and amide hydrogen exchange rates of DTPA-bis(butylamide), DTPA-bis(glucamide), and their lanthanide(III) complexes
}

\author{
Hendrik Lammers ", Anna M. van der Heijden ", Herman van Bekkum ", \\ Carlos F.G.C. Geraldes ${ }^{b}$, Joop A. Peters ${ }^{\text {a.* }}$. \\ "Laboratory of Organic Chemistry and Catalysis, Delft University of Tec/mology. Julianalaan 136. 2628 BL. Delff. The Netherlands

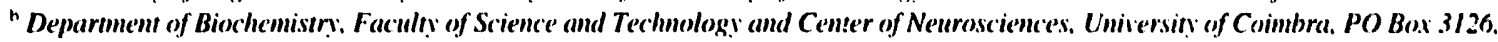 \\ 3000 Coimbra. Portugal
}

Received 1.3 June 1997: revised 5 September 1997: accepted 17 Octoher 1997

\begin{abstract}
The macroscopic and microscopic protonations of DTPA-GlucA (DTPA-bis (glucamide) ) have been investigated using potentiometry. 'H and ${ }^{1} \mathrm{C}$ NMR. The protonation behavior appears to be similar to that of the corresponding bis(alkylamides), showing that it is not affected by the prevence of the polyhydroxy side chains. Consideration of the various possible protonation pathways leads to the conclusion that the differences in basicity of the amino functions in DTPA and DTPA-bis (amides) result in different protonation sequences of these ligands. which is refiected in the macroscopic protonation constants. The significance for the design of DTPA-based contrast agents for MRI is discussed. Exchange rates of the amicle NH of this compound and that of DTPA-bis(butylamide) (DTPA-BuA $A_{2}$ ) were determined via longitudinal relaxation ralle measurements of the ande ' $\mathrm{H}$ resonances in $\mathrm{H}_{2} \mathrm{O}-\mathrm{D}_{2} \mathrm{O}(9: 1)$ as solvent. The reaction is strongly base catalyzed and the rate increase: substantially upen coordination of the DTPA-bis( mmide) by La(III). (o) 1908 Elsevier Science S.A. All rights reverved.
\end{abstract}

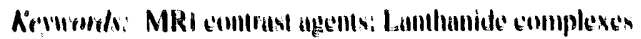

\section{Introduction}

Paramagnetic contrast agents are becoming increasingly importunt in biomedical diagnostics with the use of magnetic resonance imaging (MRI) ||$-3 \mid$. About a third of the MRI scans are nowadays conducted after the administration of these agents $|4|$. Their action is based on the enhancement of the relaxation rates $\left(1 / T_{1}\right.$ and $\left.1 / T_{2}\right)$ of water protons in the body. since these parameters contribute to the intensity of the MRI signal. Contrast agents allow, for example, an easier recognition of discased tissue. The Gd (III) complexes of diethylenetriamine- $N, N, N^{\prime}, N^{\prime \prime} . N^{\prime \prime}$-pentaacetate (Gd(DTPA $)^{2-}$, 1, 1,7, 10-tetratazacyclododecane- $N . N^{\prime}, N^{\prime \prime}, N^{\prime \prime \prime}$-tetraacetate (Gd(DOTA) ), and derivatives thereof are currently being employed in medical diagnosis. The fast evolution of the MRI technique has caused an increasing demand for more effective and more specific contrast agents.

Theory predicts that it should be possible to have contrast agents with relaxivities ( relaxation rate enhancement per $\mathrm{mM}$

\footnotetext{
* Corresponding author. Tel.: +31-15-278 5892: fax: $+31-15-2781415$.
}

Gd( III) ) that are 50 times higher than those of agents presently applied |3|. Design of contrast agents with higher efficacy requires fine-tuning of the various parameters that determine the relaxivity and. therefore, a thorough knowledge of structure-relaxivity relationships. An option to achieve a higher relaxivi? involves the attachment of low molecular weight Grd(III) chelates to macromolecules such as polysaccharides $[5,6]$. The resulting contrast agents will have a prolonged residence time in the intravascular blood pool space and. therefore. may be useful in magnetic resonance angiography.

An important factor in the evaluation of contrast agents for MRI is the stability of these metal complexes under physiological conditions. Conditional stability constants at pH 7.4 are, in this regard, more meaningful than the thermodynamic stability constants 17]. Conditional stability constants can be calculated from the thermodynamic stability constants with the use of protonation constants. Since the thermodynamic stability of a $\operatorname{Ln}($ III) complex of polyaminocarboxylate is related to the summed protonation constants of the free ligand [8,9], insight into structural effects on these constants is 


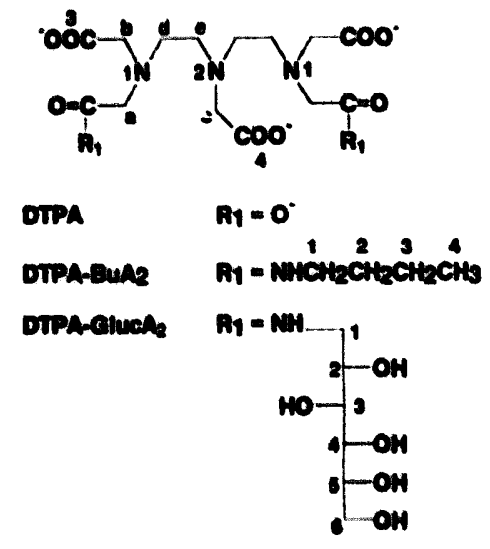

Fig. I. Structures of compounds studied.

desirable. Previously, it has been reported that the second protonation constants of DTPA-bis (amides) are about $4 \log$ units lower than those of the parent compound DTPA [10.11]. It was proposed that a possible explanation is the stabilization of some of the protonated forms by hydrogen bonding networks. In the present investigation, the macroscopic and microscopic protonation constants of DTPAbis (butylamide) (DTPA-BuA , see structures in Fig. 1) and DTPA-bis (glucamide) (DTPA-GlucA $_{2}$ ) are studied in detail by means of potentiometry and measurements of the $\mathrm{pH}$ dependence of NMR shifts. The NMR measurements are conducted in a water $=D_{3}, 0$ mixture $(9: 1$, vol./vol.), to allow observation of the amide protons. The exchange of these protons between the amide group and water as a function of pH is investigated as well. The effects of coordination by La(III) on these parameters are evaluated. DTPA.GlucA was included in this study because it can serve as a model compound for conjugutes of DTPA and polysaceharides $|12|$.

\section{Experimental}

\subsection{Materials}

Water used in the potentiometric titrations and in the NMR measurements was demineralized. All chemicals were purchased from Aldrich unless specified otherwise and were used without further purification. Lanthanum chloride was used as a mixed hydrate. The La(III) content was determineu by complexometric titration with xylenol orange as the indicator [13]. The DTPA-bis(amides) DTPA-GlucA, $\{12\}$ and DTPA-BuA $A_{2}[10]$ were synthesized as described previously. La(III) complexes of these ligands were prepared by mixing solutions of equimolar amounts of hydrated $\mathrm{LaCl}_{3}$ and ligand. The absence of free $\ln ($ III) was verified using a xylenol orange indicator $\mid 13\}$.

\subsection{Potentiometry}

Potentiometric titrations were conducted at $298 \mathrm{~K}$ in a double-walled vessel. The measurements were performed with a combined glass electrode, in which the $3 \mathrm{M} \mathrm{KCl}$ of the reference compartment was replaced by a saturated $\mathrm{NaCl}$ solution. Millivolt readings obtained were converted to $\mathrm{pH}$ values using a calibration curve, which was determined from siaindard buffer solutions. The ionic strength was maintained at $0.1 \mathrm{M}$ using $\mathrm{NaClO}_{4}$. The protonation constants were determined by titration of a $0.01 \mathrm{M}$ ligand solution with $0.02 \mathrm{M}$ $\mathrm{HCl}$. Calculations for the potentiometric titrations were performed using a spreadsheet program described previously $[14,15]$.

\subsection{NMR measurements}

'H NMR spectra were recorded on Varian VXR-400 S NMR and Varian Unity 500 spectrometers with $D_{2} O$ is the solvent and $\mathrm{t}-\mathrm{BuOH}$ as the internal reference $(\delta(\mathrm{ppm})$; 1.20). The 'H NMR pH titration curves and the amide hydrogen exchange rates of the bisamides and their La(III) complexes were measured with $0.04 \mathrm{M}$ solutions in $\mathrm{H}_{2} \mathrm{O}-\mathrm{D}_{2} \mathrm{O}$ (9:!, vol./vol.). The pH was adjusted to about 0 using $1 \mathrm{M}$ $\mathrm{HCl}$ and subsequently raised to 12 in intervals of approximately 0.5 using diluted aqueous $\mathrm{NaOH}$. The $\mathrm{pH}$ was measured with a calibrated ZII,344-I Aldrich combination $\mathrm{pH}$ electrode. The values given are direct meter readings. ${ }^{13} \mathrm{C}$ NMR spectra were recorded on a Nicolet NT-200 WB, a Varian XL-200 NMR ( $50.3 \mathrm{MHz}$ ), or on a Varian VXR-400) S NMR spectrometer ( $100.6 \mathrm{MHz}$ ) using $\mathrm{t}-\mathrm{BuOH}$ ( $\delta(\mathrm{ppm})$; $31.2)$ as the internal reference. The "'C NMR pH titration curves at $25^{\circ} \mathrm{C}$ were measured in a similar way as described for the 'H NMR pH titration curves, but now using a $0.25 \mathrm{M}$ solution of the ligand in $D_{2} O$. Longitudinal relaxation times $\left(T_{1}\right)$ were measured with the use of an inversion recovery pulse sequence with a composite $180^{\circ}$ pulse.

The complet syectral ussignment of DTPA-Gluc $A_{2}$ was carried out by means of ' $H$ homonuclear correlation spectroscopy (COSY) and ' $H={ }^{\prime \prime} C$ chemical shift correlation spectroscopy (HETCOR).

The EXSY spectrum of DTPA-BuA $A_{2}$ was recorded with a $0.04 \mathrm{M}$ sample in $\mathrm{H}_{2} \mathrm{O}-\mathrm{D}_{2} \mathrm{O}(9: 1)$ as solvent, using a sweep width of $295 \mathrm{~Hz}$ centered around the amide 'H signals (8.6= $8.9 \mathrm{ppm}$ ). The mixing time was $0.3 \mathrm{~s}$. Data were collected with 576 data points in $F_{2}$ and 24 data points in $F_{1}$. Pure absorption spectra were obtained by employing the StatesHaberkorn method $[16 \mid$. The obtained data matrix was zerofilled to $1024 \times 1024$ data points und processed using Gaussian weighting.

\section{Results and discussion}

\section{I. Ligand protonation using potentiometry and NMR pH ritration curves}

The macroscopic protonation constants ( $\log K_{i}$ ) of DTPAGluc $A_{2}$, as obtained with potentiometry, are given in Table 1. For comparison. previously determined data of DTPA-BuA ${ }_{2}$ 
Table I

Protonation constants for various DTPA-his (amide) derivatives and DTPA in $0.1 \mathrm{M} \mathrm{NaClO}_{4}$ at $25^{\circ} \mathrm{C}^{\text {* }}$

\begin{tabular}{lcllll}
\hline & $\log K_{1}$ & $\log K_{2}$ & $\log K_{3}$ & $\log K_{4}$ & $\log K_{5}$ \\
\hline DTPA-GlucA $_{2}{ }^{n}$ & 9.2 & 4.5 & 3.3 & 2.3 & $\mathrm{~d}$ \\
DTPA-BuA $_{2}{ }^{*}$ & 9.2 & 4.5 & 3.2 & $\mathrm{~d}$ & $\mathrm{~d}$ \\
DTPA $^{*}$ & 10.2 & 8.6 & 4.2 & 2.9 & 1.8 \\
\hline
\end{tabular}

"All values are within \pm 0.1 . The protonation constants are defined as $\left.K_{i}=\left\{H_{i} L \mid\right\}\left(H^{*} \| H_{i}, L\right)\right\}$.

"This work.

' Ref. $|10|$, in $0.1 \mathrm{M} \mathrm{NaCl}$

"Not determined.

and DTPA [10] have been included. In general, three protonation constants for the DTPA-bis (amide) ligands as well as for DTPA can be determined using potentiometry. The $\log K_{i}$ values for DTPA-GlucA $A_{2}$ are similar to those of other DTPA-bis( amides), showing that the sugar residues have no significant influence on the protonation of the DTPA moiety.
Typically, these compounds have a $\log K_{2}$, which is four units lower than that of DTPA.

Chemical shift titration curves of DTPA-BuA $A_{2}$ and DTPA-

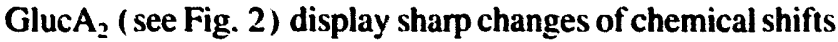
at $\mathrm{pH}$ values near the $\log K_{i}$ values. The positions of the inflection points agree with the potentiometrically determined protonation constants. The shapes of the ' $H$ chemical shift curves are similar to those of the previously studied DTPAbis(alkylamides) [10]. A closer inspection of these curves shows that the ' $\mathrm{H}$ chemical shifts for one of the terminal $\mathrm{CH}_{2} \mathrm{CO}$ functions are almost $\mathrm{pH}$ independent for $6<\mathrm{pH}<12$. whereas the other shows a $\mathrm{pH}$ jump of about $0.14 \mathrm{ppm}$ at $\log K_{1}$. We assign the latter $\mathrm{CH}_{2} \mathrm{CO}$ signal to the amide methylene group, because a similar $\mathrm{pH}$ jump was not observed in the $\mathrm{CH}_{2} \mathrm{CO}$ resonances of DTPA [10].

A quantitative estimate of the microscopic sites of protonation of DTPA-Gluc $A_{2}$ and DTPA-BuA $A_{2}$ was made with the ' $H$ NMR pH titration curves for the remaining protons in the DTPA backbone, following the empirical procedure of
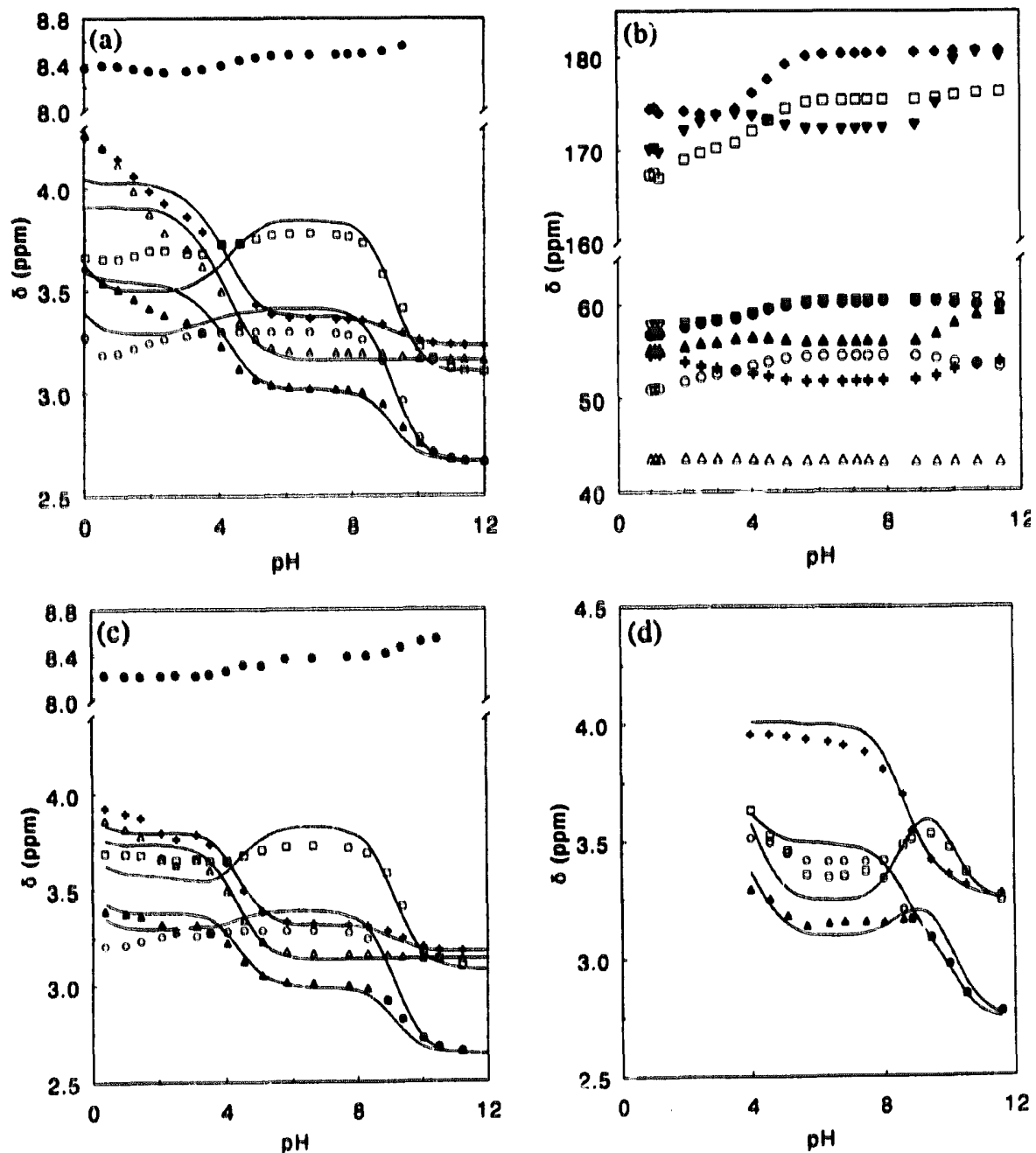

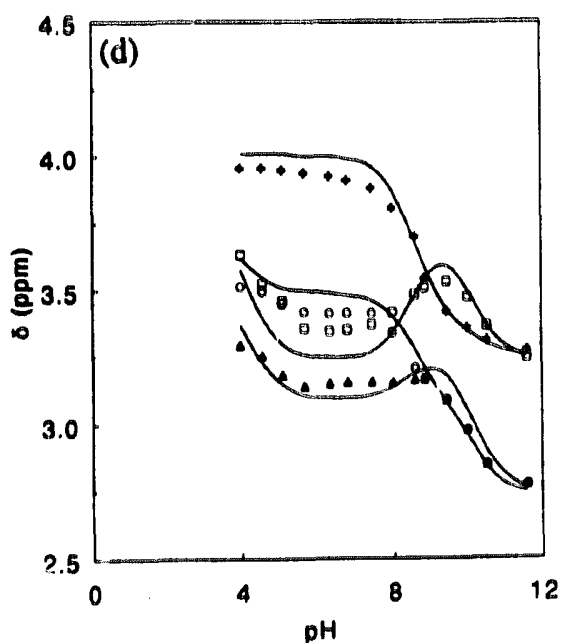

1Fig. 2. Chemical shift titration curves at 25' $\mathrm{C}$. The curves ale calculated using the microscoppic protonation constants listed in Table 4. For labeling of nuclei.

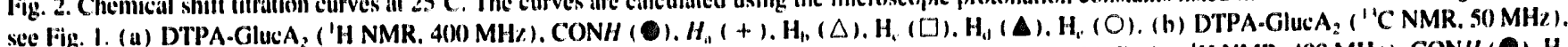

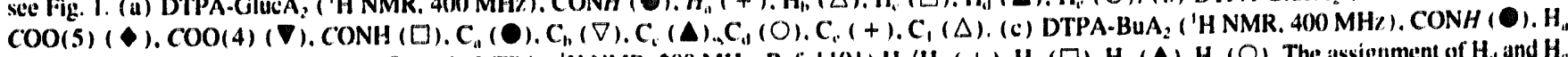

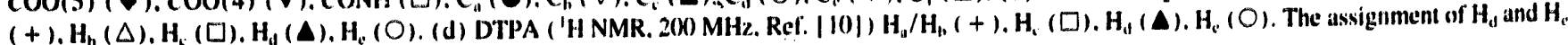
has been interchanged in Ref. | $10 \mid$. 
Sudmeier and Reilley $|17|$. The protonation of amino or carboxylate groups in the DTPA backbone will result in a deshielding of the non-labile hydrogens and changes in chemical shifts indicate the site of protonation. The observed average chemical shift of nucleus $i$ is given by $\delta_{\text {obs }}^{i}=\sum \delta_{n}^{i} X_{\mathrm{H}_{n} \mathrm{~L}}$. where $\delta_{n}^{i}$ are the proton intrinsic chemical shifts of the $\mathrm{H}_{n} \mathrm{~L}$ species and $X_{\mathrm{H}_{\mathrm{HL}} \mathrm{L}}$ is the mole fraction of each species. This equation can be rearranged to $\delta_{\mathrm{obs}}^{i}=\delta_{\mathrm{L}}+\Sigma V_{n}^{i} X_{\mathrm{H}_{\mathrm{g}} \mathrm{L}}$ in which $V_{n}^{i}$ is the chemical shift difference between $\mathrm{H}_{n} \mathrm{~L}$ and the unprotonated form $\mathrm{L}$. Speciations at various $\mathrm{pH}$ values were calculated from the protonation constants obtained from potentiometry, the ligand mass balance and the equilibria equations. The $V_{n}^{i}$ values were calculated for each set of shift data using a multiple linear regression program. which minimizes the sums of the squares of the deviation between the observed and calculated values $\delta_{\text {st. }}^{i}$. The $V_{n}^{i}$ values obtained for the various forms $H_{n} L$ were then used to calculate the fractions of protonation of the nitrogen $(N)$ and of the carboxylate $(O)$ sites $\left(f_{N}\right.$ and $f_{O}$, respectively). The average number of ligand bound protons at all basic sites is $n=$ $\alpha_{N} f_{N}+\alpha_{O} f_{O}$. where $\alpha_{N}$ and $\alpha_{G}$ are the number of equivalent $\mathbf{N}$ and $\mathbf{O}$ sites, respectively. It has been shown for linear poly(aminocarboxylate) chelates that the effects of protonation at various basic sites $\left(V_{n}^{\prime}\right)$ are additive and can be calculated $\left(V_{m(t)}^{\prime}\right)$ using $|17|$ :

$V_{n \in 1}^{\prime} \equiv \sum C_{N_{1}} f_{N}+\sum C_{N^{\prime}} f_{N}+\sum C_{N^{\prime}, f_{N}}+\sum C_{0}, f_{o}$

where the $\mathrm{pH}$-independent shielding constants $C_{0} \equiv 0,20$. $C_{\mathrm{N}} \equiv 0.75$ and $C_{\mathrm{N}} \equiv 0.35 \mathrm{ppm}$ can be used. The latter constants are the changes in proton chemical shift of the $\mathrm{CH}_{2}$ groups under study, due to a-curboxylate protonation $\left(C_{0}\right)$ of protonation of an $\mathrm{N}$ atom in the a-position $\left(C_{N}\right)$ or in the Boposition $\left(C_{N}\right)$. To account for the $\mathrm{pH}$ jump observed in the $\mathrm{CH}_{3} \mathrm{CONHR}$ protons, a new shielding constant $\mathrm{C}_{\mathrm{N}^{\prime \prime}} \equiv 0.14$ was included for the shielding of these protons upon protonatton of the adjacent amino group. The values of $f_{\mathrm{N}}$ and $f_{\mathrm{o}}$ were calculated through minimization of the sum of the squares of the differences between the culculated and observed protonation shifts ( $V_{n+c}^{\prime}$, and $V_{n}^{\prime}$, respectively). In Table 2 the resulting values of $f_{N}\left(f_{1}, f_{2}\right)$ and $f_{0},\left(f_{1}, f_{4}\right)$ are compared with those obtained previously for DTPA $(10 \mid$.

\section{Table 2}

Percent prokonation fractions of the vifferen hasic siles of DTPA.CBlucA. compated with DTPA and various DTPA-bist anide) derivatives for differ. ent values of a ( for identiticution of $f$, sites, see Fig. 11 . The errose of $f$, are $\pm \$$

\begin{tabular}{|c|c|c|c|c|c|}
\hline & $n$ & $h$ & 1. & i. & h \\
\hline DTPA-GlWA, & $\begin{array}{l}1 \\
2\end{array}$ & $\begin{array}{r}4 \\
57\end{array}$ & $\begin{array}{l}\text { (9) } \\
\text { (5) }\end{array}$ & $\begin{array}{l}0 \\
0\end{array}$ & 13 \\
\hline DTPA=BUA: & $\begin{array}{l}1 \\
2\end{array}$ & $\begin{array}{r}5 \\
53\end{array}$ & 87 & $\begin{array}{l}0 \\
6\end{array}$ & 12 \\
\hline DTPA " & $\begin{array}{l}1 \\
2\end{array}$ & $\begin{array}{l}36 \\
87\end{array}$ & $\begin{array}{l}41 \\
16\end{array}$ & $\begin{array}{l}0 \\
0\end{array}$ & $\begin{array}{l}0 \\
5\end{array}$ \\
\hline
\end{tabular}

"Ref. (10).
The data clearly show that the first protonation $(n=1)$ occurs predominantly at the central diethylenetriamine backbone nitrogen $\left(f_{2}\right)$ for the DTPA-bis(amides), whereas in DTPA the central and the terminal nitrogen atoms have about ey: al basicity. Previously, it has been proposed that this differer $e_{i}$ in behavior and the large difference in $\log K_{2}$ values betweel: : TPA and DTPA-bis( amides) may be ascribed to stabilization of unprotonated and monoprotonated DTPAbis( amide) species relative to the corresponding DTPA species. as a result of a bifurcated hydrogen bond between the amide hydrogen and the neighboring amine $\mathrm{N}$ and carboxylate $\{10,11\}$.

To allow observation of the amide resonances, the present measurements were performed in a mixture of $\mathrm{H}_{2} \mathrm{O}$ and $\mathrm{D}_{2} \mathrm{O}$ $(9: 1$, vol./vol.). The water signal was suppressed by presaturation with the transmitter in combination with a spin-echo pulse sequence. In this way a triplet for amide protons $\left({ }^{3} \mathrm{~J}=5.6 \mathrm{~Hz}\right)$ was observed at $\mathrm{pH}<10$. The linewidth of the amide proton increased between $\mathrm{pH} 6$ and 10. indicating an increase in exchange rate upon raising the $\mathrm{pH}$ (see below). Above $\mathrm{pH} 10$ the signal was no longer observable, probably because of excessive exchange broadening or by suppression of the amide resonance together with that of water because of very fast exchange between these protons. The chemical shift curves for the amide protons and the adjacent $\mathrm{CH}_{2}$ function showed relatively small jumps at the various $\log K_{i}$ valIIes $(<0.2 \mathrm{ppm})$. These may be ascribed to the protonations of the diethylenetriamine moiety or to disruption of intramolecular hydrogen bonds.

A quantitative evaluation of the "C NMR pH titrution curves of DTPA-Glue $A_{\varepsilon}$ (Fig. 2) was not possible. bectuse the diethylenetriamine carbons showed downliced shilis upon protonation of une of the neighboring nitrogens. The "C protonation shifts lor comparable carbon atoms in annino acids reported in the literatur: are usually positive $\mid 18-211$. Downfield protonation shifts have also been observed in "C shift curves for carbons in the diethylenetriamine backbone of DTPA | 22.23|. Probably. the "C chemical shifts are more sensitive to conformational changes accompanying the protonation than ' $H$ shilts and. consequently, the common effects for the "C chemical shifts are no longer valid. The trends observed in the titrution curves ( Fig. 2), however, agree with the $f$ values obtained from the evaluation of the ' $H$ data (Table 2).

The ' $H$ and "C chemicul shilts of the sugar moiety of' DTPA.Giluc $A_{2}$ are almost independent of the pH (maximum variation of $0.07 \mathrm{ppm}$ in ' $\mathrm{H}$ shifts and $0.5 \mathrm{ppm}$ in ${ }^{1}$ 'C shifts between $\mathrm{pH}(0$ and 12 ), showing that its hydroxyl groups are not involved in intramolecular hydrogen bonds with the DTPA backbone. Accordingly, the vicinal $\mathrm{HH}$ coupling constants (Table 3) are almosit the same as those of sorbitol (Dglucitol) (24) and are independent of the $\mathrm{pH}$. It can be concluded that the conformation of the sugar side chain is the same as that of sorbitol in solution, which is similar to the solid state structure. 
Table 3

The proton coupling constants $(\mathrm{Hz})$ of the sugar chain in DTPA-Gluc $\mathrm{A}_{2}$ "at $400 \mathrm{MHz}$ and $25^{\circ} \mathrm{C}$ compared with those of sorbitol ${ }^{\text {s }}$

\begin{tabular}{|c|c|c|c|c|c|c|c|c|c|}
\hline & $\boldsymbol{J}_{1,1}$. & $3_{1,2}$ & 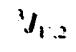 & $I_{23}$ & ${ }^{3} J_{3,4}$ & $3_{4.5}$ & $3_{5,6}$ & $3_{5.6}$ & $\boldsymbol{2}_{\boldsymbol{H}, \mathrm{B}}$ \\
\hline DTPA-GlucA: & -14.0 & 4.0 & 8.0 & 5.5 & 2.3 & 8.0 & 3.0 & 6.0 & -11.5 \\
\hline D-Sornitol & -12.0 & 3.6 & 6.6 & 6.0 & 1.8 & 8.3 & 3.0 & 6.3 & -11.8 \\
\hline
\end{tabular}

a The carbon atom adjacent to the amide group has number 1 .

'Ref. [24].

The 'H NMR spectra of La(III) complexes of DTPAGluc $A_{2}$ and DTPA-BuA 2 showed the presence of various isomers. Four well-separated amide signals were observed

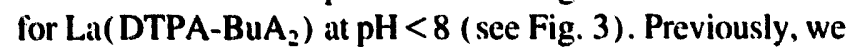
have shown that DTPA-bis(amides) are coordinated by Ln( III) cations in an octadentate fashion via the three nitrogen atoms of the diethylenetriamine moiety, the three carboxylate oxygens, and the two amide oxygens $[12,25]$. The first coordination sphere is completed by a water molecule. The inversion of the three nitrogens of the diethylenetriamine unit is precluded upon coordination. Consequently, they become chiral in the complex and the ligand can occur in eight enantiomeric forms (four diastereomeric pairs). In the static situation, this would lead to eight signals for, for example, the amide hydrogens of La(DTPA-BuA $\left.A_{2}\right)$. Two major dynamic processes play a role in the DTPA-bis(amides) [25-27]. Wagging of the ethylene units between two gauche conformations results in racemization at the central nitrogen atom. Furthermore, racemization of the terminal nitrogens is possible. but that requires decoordination of the concerning nitrogen and its adjacent $\mathrm{COO}$ and amide $\mathrm{CO}$ functions. Consecquently, the latter exchange process is relatively slow. The observation of lour annide eriplets in the 'H spectra of DTPA-BuA shows that the wagging motion is rapid on the NMR time seale. The exchange via racemization of the terminal nitrogen atoms was demonstrated by a two-dimen-

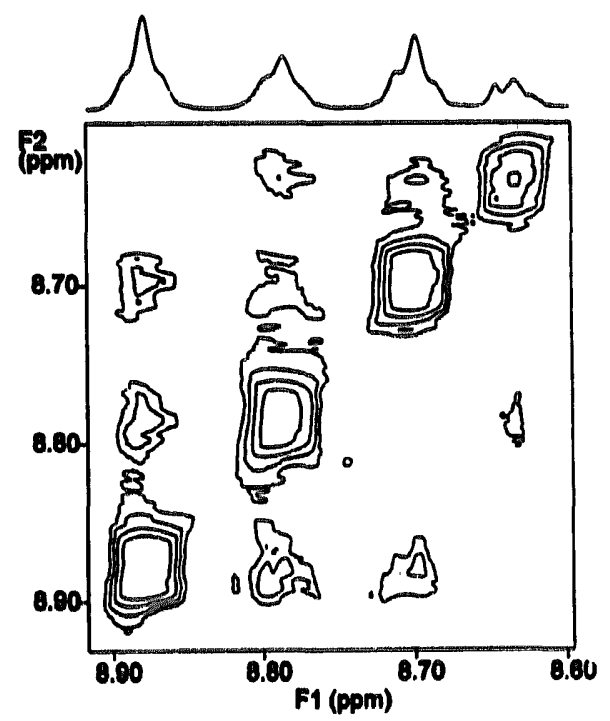

Fig. 3. 2D EXSY spectrum for the anide region of the 'H spectrum of 0.04 $\mathrm{M} \mathrm{La}\left(\mathrm{DTPA}-\mathrm{BuA}_{2}\right)$ in $\mathrm{H}_{2} \mathrm{O}-\mathrm{D}_{2} \mathrm{O}\left(9: 1, \mathrm{vol} / \mathrm{vol}\right.$.) at $25^{\circ} \mathrm{C}$. $\mathrm{pH} 4.1$ and $4(X) \mathrm{MHz}$. sional EXSY spectrum (see Fig. 3). Each amide resonance has cross-peaks for exchange with two others, identifying the racemization at the two terminal amino nitrogens. No crosspeak is observed with the fourth isomer, obviously because that would require synchronous racemization of both terminal nitrogens. This exchange process is extremely slow because it requires decoordination of both terminal ends of the ligand. The NMR spectra of La(DTPA-Gluc $A_{2}$ ) were more complex. Because of the chirality of the amide side chains, the number of resonances is twice as large here [12].

The resonances for the amide protons of these $\mathrm{La}$ (III) complexes broadened upon an increase of the $\mathrm{pH}$ and above $\mathrm{pH} 8$ they were not observable. This can again be ascribed to the increasing rate of exchange between the amide hydrogens and bulk water. The chemical shifts were almost $\mathrm{pH}$ independent between $\mathrm{pH} 2$ and 8 . Upon a decrease of the $\mathrm{pH}$ below 2 , all four amide resonances of La( DTPA-BuA $A_{2}$ ) gradually shifted downfield ( see Fig. 4) and decreased in intensity. The signals of the free ligand. however, were at an upfield position with respect of these signals. Therefore, this downfield shift cannot be explailied by exchange between complex and free ligand. Mosi likely, this phenomenon is the result of protonation of the ligand. probably at the non-coordinuted curboxylate oxygens. These spectra show the large stability of these La(III)-bisamide complexes under acidic

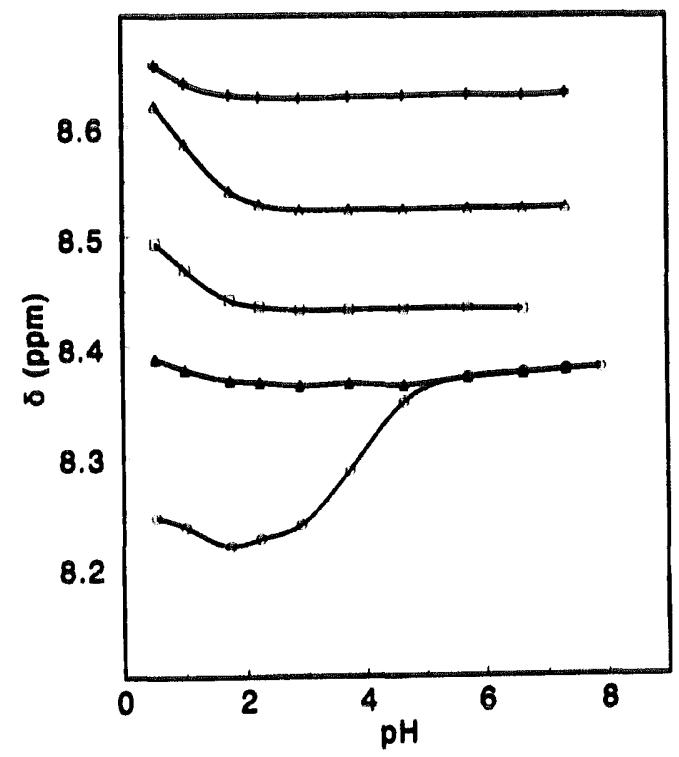

Fig. 4. 'H chemical shift titrations of the amide region of $0.04 \mathrm{M} \mathrm{La(DTPA}$ $\left.\mathrm{BuA}_{2}\right)$ in $\mathrm{H}_{2} \mathrm{O}-\mathrm{D}_{2} \mathrm{O}(9: 1$, vol./vol.) $(+. \Delta$. $\square$. $\Delta)$. An excess of free ligand $(10$ mol.\%) $(O)$ was present in the sample. 


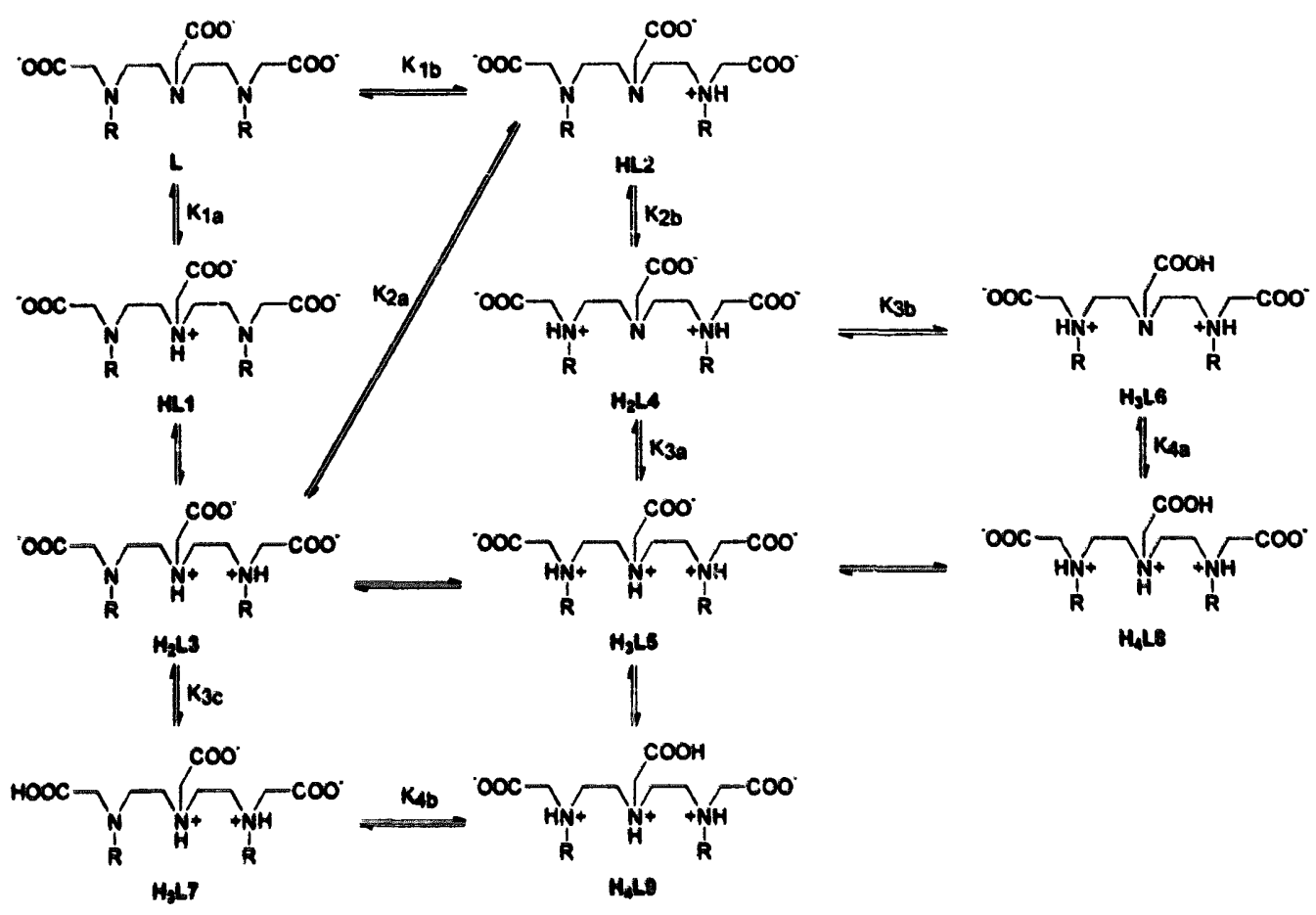

Fig. 5. Protonation sequences of DTPA and derivatives.

conditions, which is a result of the relatively low basicity of these ligands with respect to DTPA.

\subsection{Protonation pathways of DTPA and its bis(amides)}

The approach of Sudmeier and Reilley [17] for the anal. ysis of chemical shift titrations of uminopolycarboxylutes provides information on 'averaged' protonated species al var. lous degrees of protonation. This analysis showed that the first protonation of DTPA takes place on both the central und the terminal nitrogens (see above); the basicities of these amino functions are about the same. After uptake of two equivalents of $\mathrm{H}^{*}$, the protons reside predominantly at the terminal Natoms. Microscopically, the picture is more complicated. In the monoprotonated species with the proton on the central $N$ atom (HLI, see Fig. 5), the only possible second protonation is at a terminal $\mathrm{N}$-utom giving $\mathrm{H}_{2} \mathrm{~L}$. However if the first proton is at a terminal Natom (HL2), the second protonation can be either at the middle $\mathrm{N}$-atom $\left(\mathrm{H}_{2} \mathrm{~L} 3\right.$ ) or at the other terminal $\mathrm{N}$-atom $\left(\mathrm{H}_{2} \mathrm{~L} 4\right)$ ). The latter pathway is favored because it leads to less positive charge repulsion. An inspection of literature data shows that $\log K_{1}-\log K_{2}$ for 1,4-diamines with chemically equivalent amino groups is generally in the range $\mathbf{2 . 8}-4.0$, whereas for 1.7 diamines $\log K_{1}=\log K_{2}$ is only 0.6-1 |28|. Some typ= ical examples are compiled in Fig. 6.

Changes in the basicity of an N-atom in DTPA by replacement of a neighboring curboxylate group by another group have a dramatic influence on the protonation pathways. From a comparison of reported $\log K$ values of nitrilotriacetic acid with derivatives in which one of the acetic acid moieties is substituted by an amide function (see Fig. 7), it may be expected tha: substitution of a terminal carboxylate by a carboxamide function leads to a decrease of the $\log K$ of the ammonium function of about 2.5 units [28]. This effect may be ascribed to the presence of a hydrogen bond between the amide NH and the amine nitrogen atom. Therefore, the central amino function of the DTPA-bis(amides) will be the most basic one and the initial protonation will occur predominantly at that atom (HLI). Then. the second protonation step leads to a relatively unfavorable diprotonuted 1.4-diamine deriva. tive $\left(\mathrm{H}_{2} \mathrm{~L}_{2}\right)$. Consequently, the macroscopic protonation constant $K_{z}$ is dominated largely by this unfavorable step and will be relatively low, whereas in DTPA, the favorabl: pro= tonation sequence, terminal N (HL2) $\Rightarrow$ other term. atom $\left(H_{2} L 4\right)$, will give rise to a higher value of $K_{2}$.
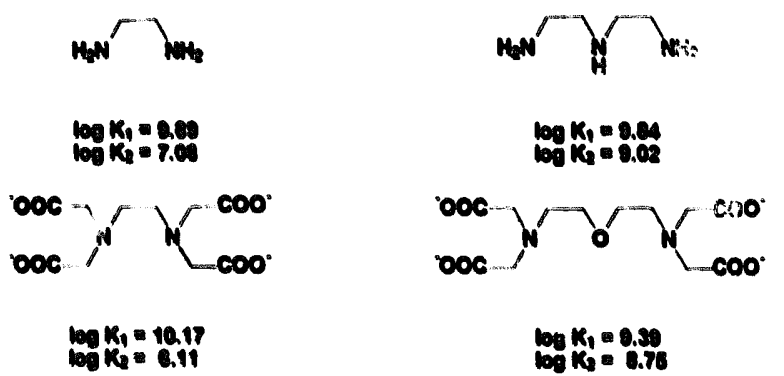

Fig 6. Some examples of protomation constants of 1.4- and 1.7-diamines reported in Ref. | $28 \mid$.

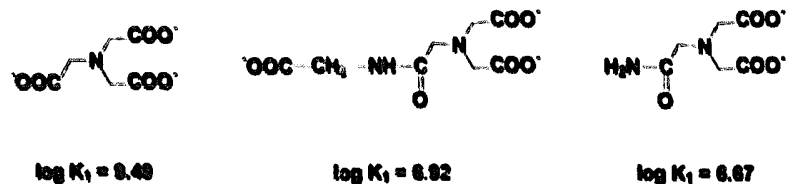

Fig. 7. Protonation constants of nitrilotriacetic acid and some derivatives |28]. 
The protonation equilibria that may play a role in the $\mathrm{pH}$ region of the chemical shift titrations are shown in Fig. 5. Too many protonation constants are involved in this model to allow for a useful fitting of the experimental data. Therefore, we have performed calculations of titration curves after including some arbitrary constraints. The value of $\log K_{1 \mathrm{a}}-\log K_{2 \mathrm{a}}$ was fixed at 2.8 and that of $\log K_{1 \mathrm{~b}}-\log K_{2 \mathrm{~b}}$ at 0.7 . From a guess of the protonation constants the distribution of the various species was calculated $[14,15]$. Then, the (exchange-averaged) chemical shifts as a function of the $\mathrm{pH}$ wire calculated from these concentrations and chemical shifts of the species estimated with the use of the $\mathrm{pH}$-independent shielding constants for the various protonation sites (see above, Eq. (1)). In addition, the macroscopic protonation constants were calculated from the speciations. Subsequently, the deviation between the observed and calculated shifts and, simultaneously, the deviations between calculated and observed macroscopic protonation constants (Table 1) were minimized by variation of the microscopic protonation constants ( see Table 4). The fits obtained are adequate (see Fig. 2); the calculated chemical shifts at $\mathrm{pH}>2$ are within $0.1 \mathrm{ppm}$ of the observed ones, which agrees with the accuracy of the chemical shifts of model compounds calculated similarly by Sudmeier and Reilley $|17|$. The difference between the $\log K$ values of HL1 and HL2 for the DTPA-bis (amides) (see Table 4) agrees well with the value expected (2.7) based on a comparison of the log $K_{i}$ values of nitrilotriacetic acid and corresponding carboxamides ( see Fig. 7). It should be stressed. however, that these calculations merely serve to demonstrate that the proposed model may explain the NMR titrution data. The microscopic protonation constants obtuined should be tretted with caution, because of the ussumptions made during the fitting procedure and because of the inuceuracy of the shielding constants used for the estimation of the chemicul shifts of the various species.

\section{Tuble 4}

Microseopic protonamion constatns" (log values) for vurious DPPA. bis ( umide) derivatives and DTPA used to calculute the NMR titration curves in Fig. 2 ( see text)

\begin{tabular}{|c|c|c|c|}
\hline & DTPA & DTPA-Gluc $A_{2}$ & DTPA-BuA, \\
\hline$\kappa_{1 u}$ & 9.94 & 9.26 & 9.17 \\
\hline$K_{11}$ & 9.69 & 6.99 & 6.97 \\
\hline$K_{2,1} n$ & 7.14 & 6.46 & 6.37 \\
\hline$K_{214}$ & 8.90 & 6.20 & 0.27 \\
\hline$K_{\text {t.1. }}$ & 3.96 & 3.14 & -4 \\
\hline$K_{2 n}$ & 3.94 & 3.40 & 3.2 .3 \\
\hline$K_{16}$ & $-1 "$ & $-1^{107 n}$ & 3.17 \\
\hline $\boldsymbol{K}_{\mathrm{d1}}$ & 322 & -0.31 & -0.10 \\
\hline $\boldsymbol{K}_{4 \mathrm{~s}}$ & -4.95 & $-" 1$ & $-" 1$ \\
\hline
\end{tabular}

"Defined for the equilibria deserihed schematically in Fig. 5. $K_{1,1}$

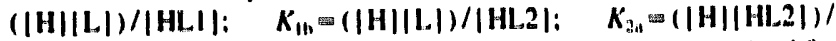
$\left|H_{2} L .3\right|: K_{21,}=(|H||H L 2|) /\left|H_{2} L 4\right|$ etc. (charges have been omitted for clarity).

"Fixed at $\log K_{1}-2.8$.

"Fixed at $\log K_{2}-0.7$

" $\leq-5$.
Protonation constants of many polyaminopolycarboxylates reported in the literature can be explained similarly. For example, bis(methyl)-DTTA (Fig. $5, \mathrm{R}=\mathrm{CH}_{3}$, DTTA = diethylenetriamine- $N, N^{\prime}, N^{\prime \prime}$-triacetate) has been reported to have $\log K_{1}$ and $\log K_{2}$ values of 10.70 and 9.09 , respectively [29]. Replacement of a terminal acetate group of DTPA by a methyl group will result in an increase of the basicity of the terminal amino function concerned. Consequently, the initial protonation will occur preferentially at the terminal amino functions and the second protonation will be predominantly at the other terminal amino function, which minimizes the charge repulsion. Therefore, the value of $\log K_{2}$ is relatively close to that of $\log K_{1}$. If, on the other hand, the central acetate group of DTPA is replaced by a methyl group, $\log K_{1}$ and $\log K_{2}$ become 10.89 and 7.39 , respectively [28]. Now, the central amino function is the most basic one and the population of the energetically unfavorable 1,4-diprotonated species ( analogous to $\mathrm{H}_{2} \mathrm{~L} 3$ ) will be high, which is in line with the relatively large difference in protonation constants.

\subsection{Finetics of the exchange of the amide hydrogens with water}

The kinetics of the amide hydrogen exchange was studied by the longitudinal ' $\mathrm{H}$ relaxation rates, which were measured with the use of an inversion recovery pulse sequence with saturation of the water resonance during the acquisition and all delays. The magnetization recovery curves obtained are $\mathrm{pH}$ dependent and are single-exponential. As outlined by Zheng et al. [30], this suggests that the involvement of the amide hydrogen in a solvent-inaccessible hydrogen bonding is negligible or that the rates of opening and closing the hydrogen bonds are fast on the NMR time scale. This is supported by the signals for the methylene hydrogens of the acetate groups and the $\mathrm{CH}_{2} \mathrm{CONH}$ functions, which both are singlets rather than $\mathrm{AB}$ systems as should be expected in case of restricted rotation due to hydrogen bonding $|3| .32 \mid$. In Fig. 8. the observed apparent longitudinal relaxation rates $\left(R_{1}\right)$ for DTPA-BuA $A_{2}$, DTPA-Gluc $A_{2}$, and the corresponding $\mathrm{La}$ (III) complexes are plotted as a function of $\mathrm{pH}$. The relaxation rates of the amide protons in the various isomers of the La(III) complexes were identical within the experimental error. If we assume that the Overhauser enhancement of the $\mathrm{NH}$ resonances by water saturation is negligible |33|. the observed rate $R_{1}$ can be expressed as the sum of the intrinsic (dipolar) relaxation ate of the amide proton $\left(R_{n}\right)$ and the exchange rate of the amide proton with water $\left(k_{\mathrm{cs}}\right)$ :

$R_{1}=R_{11}+k_{\text {ix }}$

The intrinsic relaxation rate of an amide proton is due to the dipolar relaxation of the $\mathrm{NH}$ with other $\mathrm{H}$ atoms in its proximity, which is pH! independent. The upper limit of $R_{n}$ can, therefore, be estimated from the minimum of the curves of $R_{1}$ versus $\mathrm{pH}$. The data suggest that the exchange rates under neutral and acidic conditions are relatively low ( of the same magnitude as or smaller than the intrinsic relaxation 

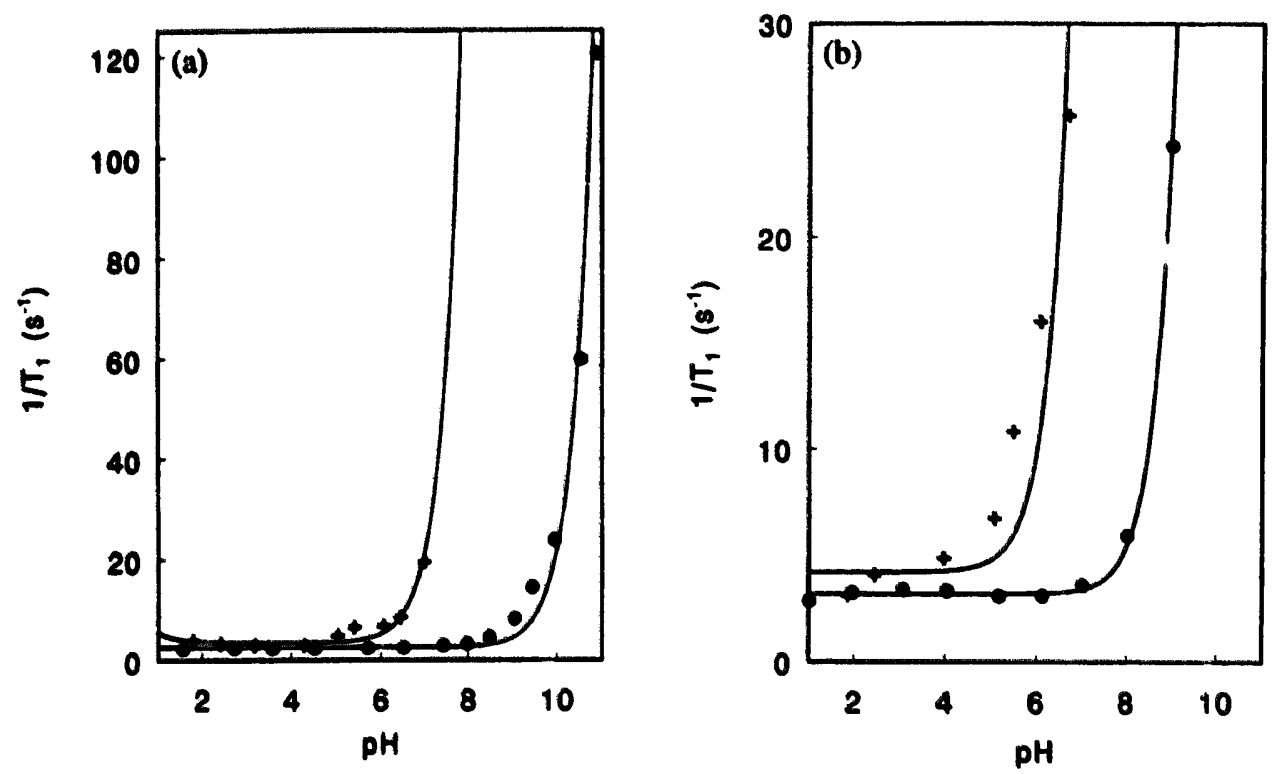

Fig. 8. Longitudital ' $H$ relaxation rates as a function of $\mathrm{pH}$ for amide protons in (a) DTPA-BuA: and (b) DTPA-GlucA 2 , and the corresponding La( III) complexes, measured in a $0.04 \mathrm{M}$ solution in $\mathrm{H}_{2} \mathrm{O}-\mathrm{D}_{2} \mathrm{O}\left(9: 1\right.$, vol. $/ \mathrm{vol}$.) at $25^{\circ} \mathrm{C}$ and $400 \mathrm{MHz}$. (O) Free ligand. ( + ) La( III) complex.

rates). Attempts to measure the exchange rates under those conditions by monitoring the integral of the resonance as a function of time upon dissolution of the compound into $D_{2} O$ failed because the exchange was already complete before the first spectrum could be recorded ( within $2 \mathrm{~min}$ ). The lower limit of the exchange rates is, therefore, about $0.01 \mathrm{~s}^{-1}$.

The exchange rates of $\mathrm{NH}$ protons commonly obey Eq, (3), where $k_{A^{\prime}}, k_{h}$ and $k_{w}$ are the rate constants for cutalysis by specific acid, specific base, and water (34):

$k_{B}, \equiv k_{a}\left|H^{*}\right| \neq k_{n}|\mathrm{OH}| \neq k_{w}$

Combination with Eq, (2) gives Eq. (4), where $C \equiv k_{w} \neq R_{t}$,

$R_{1} \equiv k_{a}\left|H^{*}\right| \neq R_{h}|\mathrm{OH}| \neq C$

Fitting of the observed relaxation rates to Eq. (4) gives the rate constants shown in Table 5.

The exchange rates in DTPA-BuA are lower than those in DTPA-Gluc $A_{2}$. Probably, this is due to steric blocking effects of the aliphatic side chains. A similar effect has been observed in peptides $|34|$. The second-order rate constants for the DTPA-bis( amides) are somewhat smaller than those of $\mathrm{N}$-methylacetanide $[\mathrm{35} \mid$ and model peptides with accessible NH groups ( see Table 5) [34]. This may be explaned by involvement of the amide protons in hydrogen bonds. reductions by one to six decades in exchange rates have been observed for protons involved in hydrogen bonding |36|.

A substantial increase of the exchange rate is observed upon complexation to La( III), which can be ascribed to the decreuse of the log $K$ of the NH function because of the electron withdrawing effect of the metal ion. Enhameements of exchange rates of amide protons upon binding to metal ions have. for example, also been observed for polyglycine peptides |37|. If it is assumed that the acidity constants are controlled by the encounter-limited rate constant for the pro= tonation of the amide anion by water ( tuken as $10^{4} \mathrm{~s}^{-1} \mathrm{M}^{-1}$ ). it can be derived that $\log K=23-\log \alpha_{n}|38|$. In this way the $\log K$ values of the amide functions are estimated to be 17.7. 16.7. 14.7. and 14.3 for DTPA-BuA . DTPA-Gluc $A_{2}$. La(DTPA-BuAz), and La(DTPA-Gluc $\left.A_{2}\right)$, respectively.

Table 3

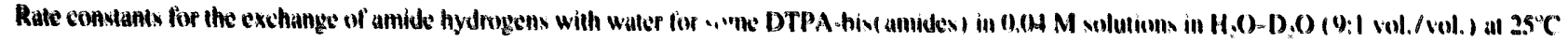

\begin{tabular}{|c|c|c|c|c|}
\hline & $k_{1}\left(M{ }^{\prime}, 1\right)$ & $A_{1},(M+1)$ & $(\cdots) 1)$ & $R_{1} \ldots \ldots$ \\
\hline DTPA.BuA & 0.0 & $1.9 \times 11^{1}$ & 2.6 & 2.2 \\
\hline DTPA=GlucA & 0.0 & $23 \times 111^{n}$ & 3.2 & 2.9 \\
\hline$N=$ Methylasetamide " & 36 & $4.2 \times 10^{n}$ & & \\
\hline$N$ Acelyl=N" methylamide " & 4.6 & $1.7 \times 10^{\circ}$ & & \\
\hline Poty=didalanine & 1.2 & $3,0 \times 10^{5}$ & & \\
\hline Lar(DTPA=BuA & 21.2 & $1.8 \times 10^{*}$ & 3.4 & 2.9 \\
\hline La( DTPA. (JinneA) & 0 & $5.5 \times 10^{*}$ & 4.2 & 3.1 \\
\hline
\end{tabular}

"Ref. [35], N.methylarmide hydrugen exchange.

"Ref. $\mid$ M 1 |, comected for temperature difference.

$C=R_{w}+R_{n}(\sec$ text).

Upper limit of the intrinsic relaxation rale $\left(R_{n}\right)$ of the amide proton. 
Coordination of an amide oxygen by La(III) thus results in a decrease of the $\log K$ with 2.5-3 units.

In the paramagnetic Gd(III) complexes, which are potential contrast agents for MRI, the mobile NH protons can, in principle, contribute to ihe transfer of magnetization to the bulk water [3]. However, the observed exchange rates for this mechanism are much too low to be efficient.

\section{Conclusions}

The presence of the polyhydroxy side chains in DTPAbis(amides) does not affect significantly either the macroscopic or the microscopic protonation of this ligand when compared with various DTPA-bis(amides) with alkyl side chains, such as DTPA-BuA2. Therefore, the basicities and thus the affinities for metal ions of the amino functions in these ligands are similar. However, a significant difference exists between the DTPA-bis(amides) and DTPA with respect to the value of $\log K_{2}$, which is substantially lower for the bis(amides). Previously, this has been ascribed to a stabilization of the non- and mono-protonated bis(amides) by bifurcated hydrogen bonds between the amide $\mathrm{NH}$ and the adjacent amino and carboxylate functions $[10,11]$. These phenomena result in a difference in preferred protonation pathways due to the decrease of the basicity of the terminal amino functions of DTPA. This may have important consequences for the design of DTPA-based contrast agents for MRI. It may be expected that derivatization of the parent compound so that the basicity of the terminal amino functions is enhanced with respect to that of the central one will lead to an increase of $\log K_{1}$ and $\log \kappa_{2}$. Generally a linear ecorrelation exists between $\sum \log K_{n}$ of polyaminopolycarboxy lates and $\log \beta$ of their metal complexes. Therefore, it may be expected that the thermodynumic stability of the Gd(III) complexes increases upon the derivatization mentioned. Any derivatization that decreases the basicity of the terminal amino function of DTPA with respect to the central one will lead to a substantial difference between $K_{1}$ and $K_{2}$ (as in the DTPA-bis(amides) ) and then, generally $\sum \log K_{n}$ and thus the thermodynamic stability of the corresponding metal complexes will decrease as well.

\section{Acknowledgements}

This investigation was carried out with the support of the Dutch National Innovation Program Carbohydrates, Akzo Nobal Central Research (ACR), the EC BIOMED 2 program (MACE project), and JNICT, Portugal (grant Praxis XXI 2/2.2/SAU/1194/95). The EC Erasmus program is thanked for funding the stay of A.M.v.d.H. at the University of Coimbra. This research has been done in the framework of the EC COST DI program 'Synthesis and Physicochemical Studies of Lanthanide and Transition Metal Chelates of Relevance to Magnetic Resonance Imaging'.

\section{References}

(I) R.B. Lauffer. Chem. Rev., 87 ( 1987 ) 901.

12) S.M. Rocklage, A.D. Watson and M.J. Carvlin, in D.D. Stark and W.G. Bradley (eds. ). Magnetic Resonance Imaging. Mosby Year Book. St. Louis, MO. 2nd edn.. 1992. Ch. 14.

[3] J.A. Peters, J. Huskens and D.J. Raber. Progr. Nucl. Magn. Reson. Spectrosc., 28 ( 1996) 283, and Refs. therein.

[4] R.C. Brasch, Radiology, 183 (1992) 1.

[5] R.C. Brasch, Magn. Reson. Med., 22 ( 1991 ) 282.

[6] P. Rongved and J. Klaveness, Carbohydr. Res., 214 ( 1991) 315.

17] W.P. Cacheris, S.C. Quay and S.M. Rocklage, Magn. Reson. Imaging. 8 (1990) 467.

[8] G.R. Choppin, P.A. Bertrand, Y. Hasegawa and E.N. Rizkalla, Inorg. Chem.. 21 (1982) 3722.

[9] G.R. Choppin. J. Less-Common Met.. 11 ( 1985 ) 193

| 10] C.F.G.C. Geraldes, A.M. Urbano, M.C. Alpoim, A.D. Sherry, K.-T. Kuan, R. Rajagopalan, F. Maton and R.N. Muller, Magn. Reson. Imaging, 2 (1995) 13.

III) D.H. White, L.A. DeLearic. T.J. Dunn, E.N. Rizkalla, H. Imura and G.R. Choppin, Inv. Radiol.. 26 ( 1991 ) S229.

$|12|$ H. Lammers, F. Maton, D. Pubanz, M.W. van Laren, H. van Bekkum, A.E. Merbach, R.N. Muller and J.A. Peters, Inorg. Chem.. 36 ( 1997 ) 2527.

|13| G. Brumisholz and M. Randin, Helv. Chim. Acta. 42 ( 1959 ) 1927.

[14] J. Huskens, H. van Bekkum and J.A. Peters, Comput. Chem.. 19 (1995) 409 .

[15| J. Huskens, H. Lammers, H. van Bekkum and J.A. Peters. Magn. Reson. Chem., 32 (1994) 691.

(16) D.J. States, R.A. Haberkorn and D.J. Ruben, J. Magn. Reson., 48 (1982) 286.

|17] J.L. Sudmeier and C.N. Reilley, Anal. Chem., 9 (1964) 1698.

| 18 | J.G. Butchelor, J.H. Prestegard, R.J. Cushley and S.R. Lipsky, J. Am. Chem. Soc.. 95 ( 1973 ) 6.358.

| $19 \mid$ A.R. Quirt, J.R. L.yerlu. Jr., I.R. Peut, J.S. Cohen. W.F. Reynnlds and M.H. Freedman. J. Am. Chem. Soc.. 96 ( 1974, eq0)

120| J.G. Butchelor, J. Fiency and G.C.K. Roherti, J. Magn. Rewon., 20 (1975) 19.

121| J.E. Surnewki, H.L. Suprenunt. I.K. Molen and C.N. Reilley. Anal. Chem.. $\$ 7$ ( 1975 ) 2116.

$122 \mid$ J.L. Surneski, H.L. Suprenant and C.N. Reilley. Spectrost, Letl. 9 (1976) 885

123| G.R. Choppin. S.A. Khan and G.C. Levy, Spectrosc. Lell. 13 ( 1980 ) $20)$.

124| G.E. Huwkes and D. Lowis, J. Chem. Soc.. Perkin Trans. II. (1984) $20 \% 3$.

125| C.F.G.C. Geraldes, A.M. Urbano. M.A. Hoefinggel and J.A. Peters. linorg. Chem., 32 (199.3) 2426.

|20| S.J. Franklin and K.N. Raymond, Inorg. Chem.. 33 (1994) 5794.

127| E. Bovens, M.A. Hocfnagel. E. Bocrs, H. Lammers. H. van Bekkum and J.A. Peters, Inorg. Chem., 35 ( 1996 ) 7679.

|28| A.E. Martell and R.M. Smith. Critical Stability Constints, Vols. 1.2 and 5. Plenum. Now York. 1974-1982.

(29) C. Puul-Roth und K.N. Raymond. Inorg. Chem.. 34 ( 1995) 1408

1.30) Z. Zineng. M.R. Gryk. M.D. Finusiane and O. Jardetzky. J. Magn. Reson. B. 108 ( 1995 ) 220

|31) R.J. Day and C.N. Reilley. Anal. Chem.. 36 (1964) 1073.

1.32| R.J. Day and C.N. Reilley. Anal. Chem.. 37 (1965) 1326.

1331 S. Waelder. L. Lee and A.G. Redfield. J. Am. Chem. Soc.. 97 ( 1975 ) 2927.

1.34| Y. Bai, J.S. Milne. L. Mayne and S.W. Englander. Proteins Struci Funct, Genet., 17 ( 1993$) 75$.

135) R.S. Molday and R.G. Kallen, J. Am. Chem. Soc.. 94 ( 1972 ) 6739

136) S.W. Englander. N.W. Downer and H. Teitelbaum. Annu. Rev. Biochem., 41 ( 1972) 903.

|37| D.L. Rabenstein and S. Libich. Inorg. Chem.. I| (1972) 2960).

|38) H. Sigel and R.B. Martin. Chem. Rev.. 82 ( 1982 ) 385 